\title{
CONVECTIVE INSTABILITY OF A STEADY FLOW IN AN ANNULUS CAUSED BY INTERNAL HEAT GENERATION
}

\author{
Andrei Kolyshkin\#, Valentina Koliskina, Inta Volodko, and IImārs Iltins \\ Faculty of Computer Science and Information Technology, Rīga Technical University, 2 Daugavgrìvas Str., Rīga, LV-1007, LATVIA \\ \# Corresponding author, andrejs.koliskins@rbs.lv
}

Communicated by Jurijs Merkurjevs

\begin{abstract}
Linear stability of convective motion in a tall vertical annulus was analysed in the paper. The base flow was generated by a non-uniform distribution of heat sources in the radial direction. The base flow velocity and temperature were obtained analytically solving the system of Navier-Stokes equations under the Boussinesq approximation. The linear stability problem was solved for axisymmetric and asymmetric perturbations by a collocation method based on the Chebyshev polynomials. Numerical results showed that there were three destabilising factors: (1) increase of the gap between the cylinders, (2) increase of the density of internal heat sources towards to the outer boundary of the annulus and (3) increase of the Prandtl number.
\end{abstract}

Key words: linear stability, Boussinesq approximation, collocation method.

\section{INTRODUCTION}

Thermal convection caused by internal heat sources distributed within a fluid is a topic of continuous interest from researchers due to numerous applications in engineering and geophysics. Models of thermal convection with internal heat generation are often used to describe processes in the Earth's mantle. Recent studies of biomass thermal conversion with the objective to obtain more efficient methods for biomass utilisation and heat production show the necessity to model complex phenomena with non-uniform distribution of heat sources (Abricka et al., 2016; Barmina et al., 2016). Linear stability analysis is one of the possible approaches that can be used to identify factors that enhance mixing and promote more efficient energy conversion. Linear stability of convective flow in a vertical planar fluid layer caused by internal heat sources with constant density was investigated previously (Gershuni et al., 1970; Gershuni et al., 1973). Stability analysis of mixed convective flow in a vertical pipe has been performed (Yao, 1987; $\mathrm{Su}$ and Chung, 2000). Linear stability of convective flow in a pipe caused by internal heat sources of constant density and radially non-uniform sources was also described (Kolyshkin and Koliskina, 2018a; 2018b). The role of thermal factors as well as the gap width between two concentric cylinders has been shown on the stability boundary for a flow (Kolyshkin and Vallancourt, 1991). Linear stability of a chemically reacting fluid in a pipe and annulus has been analysed by Koliskina et al. (2016) and Iltina et al. (2017).

In the present paper we consider the linear stability problem in a tall vertical annulus caused by internal heat generation. Suppose that a tall vertical annulus of radii $r_{1}$ and $r_{2}\left(r_{1}<\right.$ $r_{2}$ ) is filled with a viscous incompressible fluid. It is assumed that heat sources with density $Q=Q(\tilde{r})$ are distributed within the fluid. We use the system of cylindrical polar coordinates $(\tilde{r}, \varphi, \tilde{z})$ with the origin on the axis of the annulus. The flow is described by a dimensionless system of the Navier-Stokes equations under the Boussinesq approximation:

$$
\begin{aligned}
& \frac{\partial \mathbf{v}}{\partial t}+G r(\mathbf{v} \cdot \nabla) \mathbf{v}=-\nabla p+\Delta \mathbf{v}+T \mathbf{k}, \\
& \frac{\partial T}{\partial t}+G r \mathbf{v} \cdot \nabla T=\frac{1}{\operatorname{Pr}} \Delta \mathrm{T}+\frac{Q(r)}{\operatorname{Pr}},
\end{aligned}
$$

$\nabla \cdot \mathbf{v}=0$

where $\mathbf{k}=(0,0,1), \mathbf{v}$ is the velocity of the fluid, $T$ is the temperature and $p$ is the pressure. The following quantities are chosen as the measures, respectively, of length, $r_{2}$, time, $r_{2}^{2} / v$, velocity, $g \beta Q_{0} r_{2}^{3} /\left(2 \kappa \rho c_{p}\right)$, temperature, $\left.Q_{0} r_{2}^{2} / * 2 v \rho c_{p}\right)$, and pressure, $g \beta Q_{0} r_{2}^{3} /\left(2 \kappa c_{p}\right)$. Here $v$ is the kinematic viscosity, $\rho$ is the density, $\kappa$ is the thermal conductivity, $\beta$ is the coefficient of thermal expansion, $g$ is the 
acceleration due to gravity, and $Q_{0}$ is a constant. The problem is characterised by three dimensionless parameters the Grashof number, $G r=g \beta Q_{0} r_{2}^{5} /\left(2 v^{2} \kappa \rho c_{p}\right)$, the Prandtl number, $\operatorname{Pr}=v / \kappa$, and the radius ratio, $R=r_{2} / r_{1}$.

Different forms of the function $Q(r)$ can be considered. We assume a linear distribution of the form

$Q(r)=Q_{0}(1+\alpha r)$,

where $\alpha=$ const. The choice of the function $Q(r)$ in our analysis was based on the following arguments: (a) it is not difficult to obtain analytical solution for the steady state velocity and temperature distribution; and (b) such a distribution can be considered as an approximation for the case where a light beam is passing through an absorbing fluid in the radial direction. In addition, the sign of $\alpha$ indicates whether the density of internal heat sources increases or decreases in the radial direction.

The system (1)-(3) has a steady solution of the following structure:

$\boldsymbol{v}_{0}=\left(0,0, W_{0}(r)\right), T=T_{0}(r), p_{0}=C z+B$,

where $C$ and B are constants. Substituting (5) into (1)-(4) we obtain

$\frac{d^{2} W_{0}}{d r^{2}}+\frac{1}{r} \frac{d W_{0}}{d r}+T_{0}+C=0$,

$\frac{d^{2} T_{0}}{d r^{2}}+\frac{1}{r} \frac{d T_{0}}{d r}+1+\alpha r=0$.

The boundary conditions are

$\left.W_{0}\right|_{r=1}=0,\left.W_{0}\right|_{r=R}=0,\left.T_{0}\right|_{r=1}=0,\left.T_{0}\right|_{r=R}=0$,

The annulus is assumed to be closed so that

$\int_{1}^{R} r W_{0}(r) d r=0$.

The solution to (6)-(9) has the form

$$
\begin{aligned}
& W_{0}(r)=-\frac{1}{\ln R}\left[\frac{R^{2}-1}{4}+\frac{\alpha}{9}\left(R^{3}-1\right)\right] \times\left(\frac{r^{3}}{4} \ln r-\frac{r^{2}}{4}\right)-\frac{r^{2}}{16} \\
& -\frac{\alpha r^{2}}{36}+\frac{r^{4}}{64}+\frac{\alpha r^{5}}{225}-\frac{C r^{2}}{4}+A_{1} \ln r+A_{2}, \\
& T_{0}(r)=-\frac{\ln r}{\ln R}\left[\frac{R^{2}-1}{4}+\frac{\alpha}{9}\left(R^{3}-1\right)\right]+\frac{1}{4}+\frac{\alpha}{9}-\frac{r^{2}}{4}-\frac{\alpha r^{3}}{9},(1
\end{aligned}
$$

where

$$
\begin{gathered}
A_{1}=\left(\frac{4 a_{1}}{1-R^{2}}+\frac{16 a_{2}}{\left(R^{2}-1\right)^{2}}\right) \times\left[\frac{4 \ln R}{1-R^{2}}+\frac{8 R^{2} \ln R}{\left(R^{2}-1\right)^{2}}-\frac{4}{R^{2}-1}\right]^{-1}, \\
A_{2}=\frac{1}{\ln R}\left[\frac{R^{2}-1}{4}+\frac{\alpha}{9}\left(R^{3}-1\right)\right]\left(-\frac{1}{4}\right)+\frac{1}{16}+\frac{\alpha}{36}-\frac{1}{64} \\
-\frac{\alpha}{225}+\frac{C}{4}
\end{gathered}
$$

$C=\frac{4 a_{1}}{1-R^{2}}-\frac{4 a_{1} \ln R}{1-R^{2}}$,

and

$$
\begin{aligned}
a_{1}= & \frac{1}{\ln R}\left[\frac{R^{2}-1}{4}+\frac{\alpha}{9}\left(R^{3}-1\right)\right]\left(\frac{R^{2} \ln R}{4}-\frac{R^{2}-1}{4}\right)+\frac{R^{2}-1}{16} \\
& +\frac{\alpha\left(R^{2}-1\right)}{36}-\frac{R^{4}-1}{64}-\frac{\alpha\left(R^{5}-1\right)}{225} \\
a_{2}= & \frac{1}{\ln R}\left[\frac{R^{2}-1}{4}+\frac{\alpha}{9}\left(R^{3}-1\right)\right]\left[\frac{1}{16} R^{4} \ln R+\frac{5}{64}\left(1-R^{4}\right)\right] \\
& +\frac{R^{4}-1}{64}+\frac{\alpha\left(R^{4}-1\right)}{144}-\frac{R^{6}-1}{384}-\frac{\alpha\left(R^{7}-1\right)}{1575} \\
& -\frac{R^{2}-1}{2}\left\{\frac{1}{\ln R}\left[\frac{R^{2}-1}{4}+\frac{\alpha}{9}\left(R^{3}-1\right)\right]\left(-\frac{1}{4}\right)+\frac{1}{16}+\frac{\alpha}{36}\right. \\
& \left.-\frac{1}{64}-\frac{\alpha}{225}\right\} .
\end{aligned}
$$

The base flow temperature and velocity distribution is shown in Figures 1 and 2 for three values of $\alpha$, namely, $\alpha=2,1,0$ (from top to bottom). The value $\alpha=0$ corresponds to the case of a uniform density of internal heat sources.

\section{LINEAR STABILITY ANALYSIS (AXISYMMETRIC PERTURBATIONS)}

Consider a perturbed solution of the form

$\boldsymbol{v}+W_{0}(r) \boldsymbol{k}=\boldsymbol{v}^{\prime}, T=T_{0}+T^{\prime}, p=p_{0}+p^{\prime}$

We substitute (12) into (1)-(3) and linearise the equations with respect to small perturbations $\left(\mathrm{v}^{\prime}, T^{\prime}, \mathrm{p}^{\prime}\right)$. Next, we use the method of normal modes of the form

$$
\begin{aligned}
& \mathbf{v}^{\prime}(r, \phi, z, t)=\mathbf{V}(r) \exp (-\lambda t+i k z+i n \phi), \\
& T^{\prime}(r, \phi, z, t)=\theta(r) \exp (-\lambda t+i k z+i n \phi), \\
& p^{\prime}(r, \phi, z, t)=q(r) \exp (-\lambda t+i k z+i n \phi)
\end{aligned}
$$

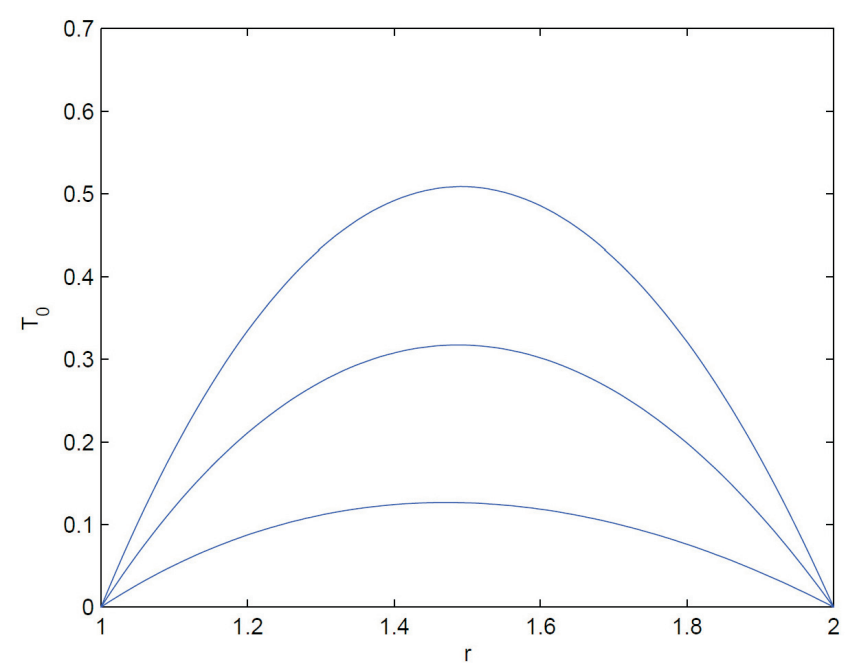

Fig. 1. The base flow temperature distribution for $R=2(\alpha=2,1,0$ from top to bottom, respectively). 


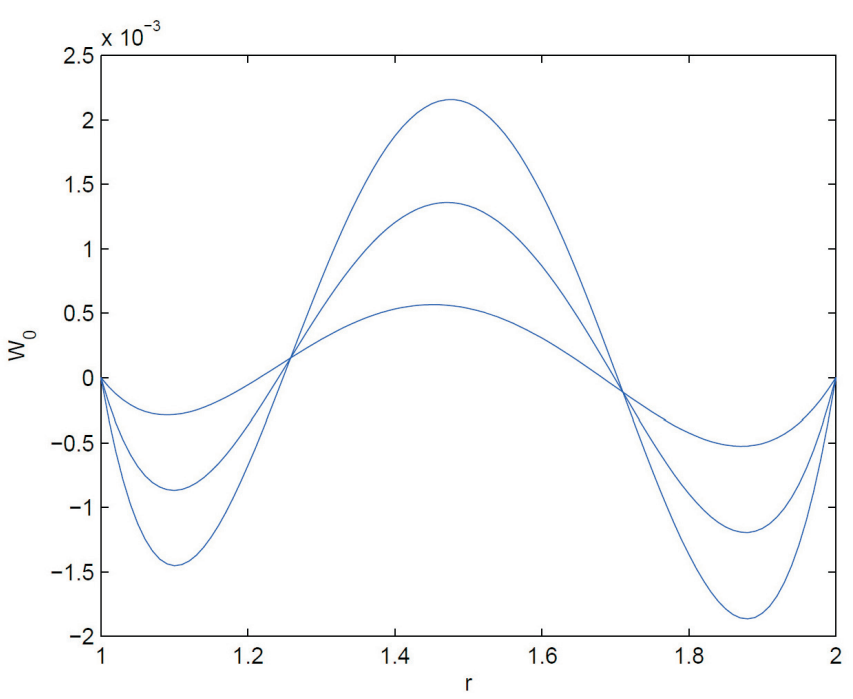

Fig. 2. The base flow velocity distribution for $R=2(\alpha=2,1,0$ from top to bottom, respectively).

where $k$ and $n$ are the axial and azimuthal wavenumbers, respectively, and $\mathbf{V}(r)=(u(r), v(r), w(r))$. It was shown in Kolyshkin and Vaillancourt (1991) that for the case of a uniform heat generation the most unstable perturbation corresponds to the mode with $n=1$ if $R>3$. However, in the region $1<R<3$ the most unstable perturbation is the axisymmetric perturbation with $n=0$. In this paper we consider both axisymmetric and asymmetric perturbations. For the case of axisymmetric perturbations with $n=0$ the vector $\mathbf{v}^{\prime}$ has the following structure: $\mathbf{v}^{\prime}=\left(v_{r}(r, z, t), 0, v_{z}(r, z, t)\right)$ so that it is convenient to introduce the stream function by the relations

$v_{r}=\frac{1}{r} \frac{\partial \psi}{\partial z}, v_{z}=\frac{1}{r} \frac{\partial \psi}{\partial r}$

where the perturbed stream function has the form

$\psi(r, z, t)=\varphi(r) \exp (-\lambda t+i k z)$.

Eliminating pressure perturbation $q(r)$ from the linearised equations we obtain

$$
\begin{aligned}
& \varphi^{(4)}-\frac{2}{r} \varphi^{\prime \prime \prime}+\left(\frac{3}{r^{2}}-2 k^{2}-i k W_{0} G r\right) \varphi^{\prime} \\
& +\left(-\frac{3}{r^{3}}+\frac{2 k^{2}}{r}+\frac{i k W_{0} G r}{r}\right) \varphi^{\prime} \\
& +\left(i k^{3} W_{0} G r+k^{4}-\frac{i k W_{0}^{\prime} G r}{r}+i k W_{0}^{\prime \prime} G r\right) \varphi-r \theta^{\prime} \\
& =-\lambda\left(\varphi^{\prime \prime}-\frac{\varphi^{\prime}}{r}-k^{2} \varphi\right)
\end{aligned}
$$$$
\theta^{\prime \prime}+\frac{\theta^{\prime}}{r}-k^{2} \theta-i k G r \operatorname{Pr}\left(\frac{\varphi T_{0}^{\prime}}{r}+W_{0} \theta\right)=-\lambda \operatorname{Pr} \theta .
$$

The boundary conditions for the original variables are
$\left.v_{r}\right|_{r=1}=0,\left.v_{r}\right|_{r=R}=0,\left.v_{z}\right|_{r=1}=0,\left.v_{z}\right|_{r=R}=0$,

$\left.\theta_{r}\right|_{r=1}=0,\left.\theta_{r}\right|_{r=R}=0$.

Since (16) is the equation of order four, we need two additional boundary conditions for the function $\varphi(r)$. These conditions can be found from the continuity equation (3). Thus, the boundary conditions for $\varphi$ and $\theta$ are

$\left.\varphi_{r}\right|_{r=1}=0,\left.\varphi_{r}\right|_{r=R}=0,\left.\varphi^{\prime}\right|_{r=1}=0,\left.\varphi^{\prime}\right|_{r=R}=0$,

$\left.\theta_{r}\right|_{r=1}=0,\left.\theta_{r}\right|_{r=R}=0$.

\section{NUMERICAL RESULTS (AXISYMMETRIC PERTUR- BATIONS)}

We seek the solution to (16), (17), (20) and (21) in the form

$\varphi(x)=\sum_{m=0}^{M+1} a_{m}\left(1-x^{2}\right)^{2} T_{m}(x)$,

$\theta(x)=\sum_{m=0}^{M+1} b_{m}\left(1-x^{2}\right)^{2} T_{m}(x)$

where $T_{m}(x)=\cos (m \arccos x)$ is the Chebyshev polynomial of the first kind of degree $m$ and $x=2 r /(R-1)-(R+$ 1) / $(R-1)$.

It follows from (19), (20) that the functions $\varphi(x)$ and $\theta(x)$ automatically satisfy the boundary conditions. The collocation method is used to discretise (16) and (17), the collocation points are

$x_{i}=\cos \frac{i \pi}{M+1}, i=0,1, \ldots, M+1$.

Substituting (20) and (21) into (16), (17) we obtain the generalised eigenvalue problem

$(A+\lambda B) \mathbf{a}=0$,

where $\mathbf{a}=\left(a_{0} a_{1} \ldots a_{M+1} b_{0} b_{1} \ldots b_{M+1}\right)^{T}$. Problem (24) is solved by Matlab routine eig.

Figure 3 plots the marginal stability curves for the case $P r=$ $0.79, R=2$ and three values of $\alpha$, representing non-uniformity of the distribution of heat sources in the fluid. The case $\alpha=0$ corresponds to uniform density of heat sources. The increase in $\alpha$ (see (4)) corresponds to the increase of the density of heat sources towards the outer boundary of the annulus. The stable region is below the curves shown in Figure 3. Thus, the increase in $\alpha$ destabilises the flow.

The marginal stability curves for the case $\operatorname{Pr}=0.79, R=1.5$ are shown in Figure 4 (the same three values of $\alpha$ are used for calculations). As can be seen from the comparison between Figures 3 and 4, the increase in $R$ also destabilises the flow.

Figure 5 plots the critical values of the Grashof number, $G r_{c}$, defined as follows: $G r_{c}=\min _{k} G r$, for the case $R=2$, $\operatorname{Pr}=0.79$. The destabilising influence of the increase in $\alpha$ (towards the outer boundary of the annulus) is clearly seen 


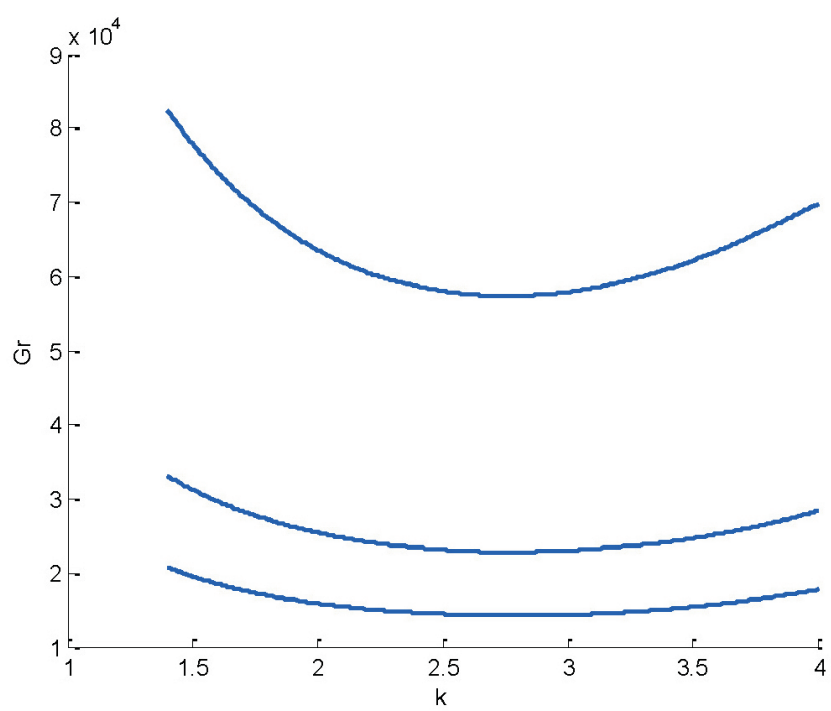

Fig. 3. Marginal stability curves for $R=2$ and three values of $\alpha: 0,1,2$ (from top to bottom).

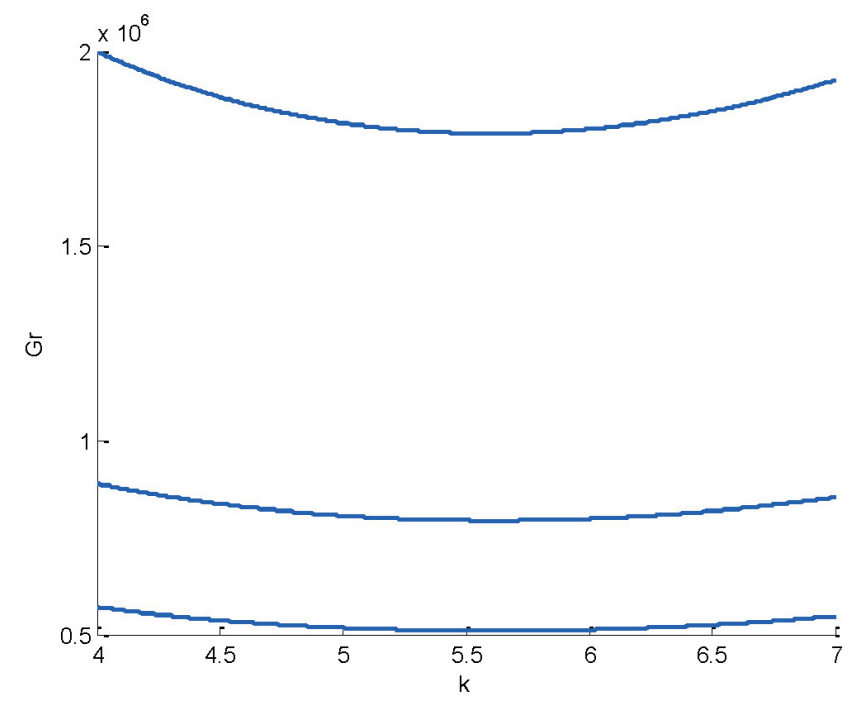

Fig. 4. Marginal stability curves for $R=1.5$ and three values of $\alpha: 0,1,2$ (from top to bottom).

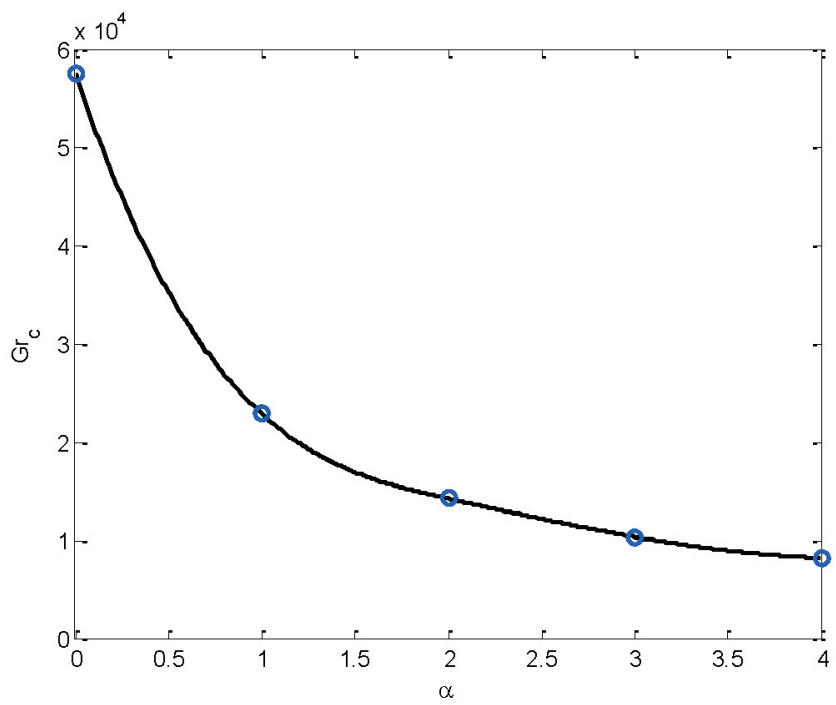

Fig. 5. Critical values of the Grashof number versus $\alpha$.

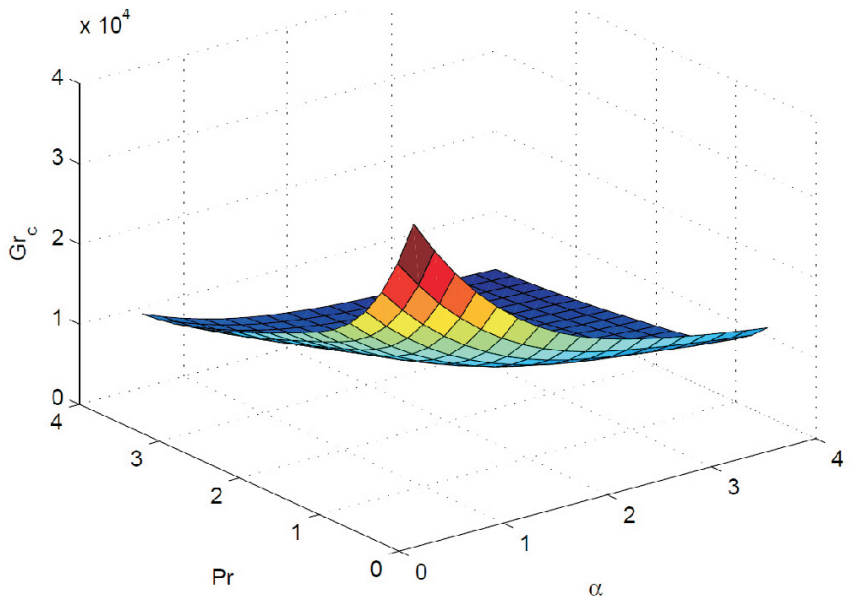

Fig. 6. Critical values of the Grashof number versus $\alpha$ and $P r$.

from the figure (the critical values $G r_{c}$ decrease as $\alpha$ increases). The dependence of the critical Grashof numbers upon $\alpha$ and $P r$ is shown in Figure 6. Here the marginal stability surface is presented (the flow is linearly stable below the surface). The increase in both $\alpha$ and $\operatorname{Pr}$ destabilises the flow.

\section{ASYMMETRIC PERTURBATIONS}

In this section we consider asymmetric perturbations of the form (13). Substituting (13) into (1)-(3) and linearising the resulting equations in the neighbourhood of the base flow (10)-(11) we obtain

$u^{\prime \prime}+\frac{u^{\prime}}{r}-\frac{u n^{2}}{r^{2}}-k^{2} u-\frac{u}{r^{2}}-\frac{2 i n v}{r^{2}}=q^{\prime}+i G r k u W_{0}-\lambda u$,
$v^{\prime \prime}+\frac{v^{\prime}}{r}-\frac{v n^{2}}{r^{2}}-k^{2} v-\frac{v}{r^{2}}+\frac{2 i n u}{r^{2}}=\frac{i n q}{r}+i G r k v W_{0}-\lambda v$,

$w^{\prime \prime}+\frac{w^{\prime}}{r}-\frac{w n^{2}}{r^{2}}-k^{2} w+\theta=i k q+G r\left(u W_{0}^{\prime}+i k \theta W_{0}\right)-\lambda w$

$\theta^{\prime \prime}+\frac{\theta}{r}-\frac{\theta n^{2}}{r^{2}}-k^{2} \theta+\theta=\operatorname{Pr} G r\left(u T_{0}^{\prime}+i k \theta W_{0}\right)-\lambda \operatorname{Pr} \theta$

$u^{\prime}+\frac{u}{r}+\frac{i n v}{r}+i k w=0$

The boundary conditions have the form

$u(1)=v(1)=\theta(1)=0, u(R)=v(R)=\theta(R)=0$,

$u^{\prime}(1)=u^{\prime}(R)=0$.

All perturbed quantities are equal to zero at $r=1$ and $r=R$. We eliminate $q(r)$ and $w(r)$ from (25) - (29) with the objective to reduce the size of the generalised eigenvalue problem obtained after discretisation. Thus, two additional boundary conditions for the function $u(r)$ (at $r=1$ and $r=$ $R$ ) are needed (these conditions are given in (31). 


\section{NUMERICAL RESULTS (ASYMMETRIC PERTURBA- TIONS)}

Calculations in this section are done for the first asymmetric mode with $n=1$ and $R=2$. The numerical method is described in Iltina et al. (2017).

The marginal stability curve for the case $\operatorname{Pr}=4, \alpha=1$ is shown in Figure 7. It is seen from the graph that the second minimum appears as the Prandtl number increases. Depending on the values of the parameters, the marginal stability curve can have a rather complicated shape: it may have a cusp (like in Fig. 7), or even a loop where two modes are unstable or even have regions where more than two modes are unstable.

Figure 8 plots the critical Grashof numbers versus $\operatorname{Pr}$ for the first asymmetric mode with $n=1$ and $R=2$. Three values of the parameter $\alpha$ are used, namely, $\alpha=0,1$ and 2 (from top to bottom). It is seen from the figure that the flow is destabilised as the Prandtl number grows.

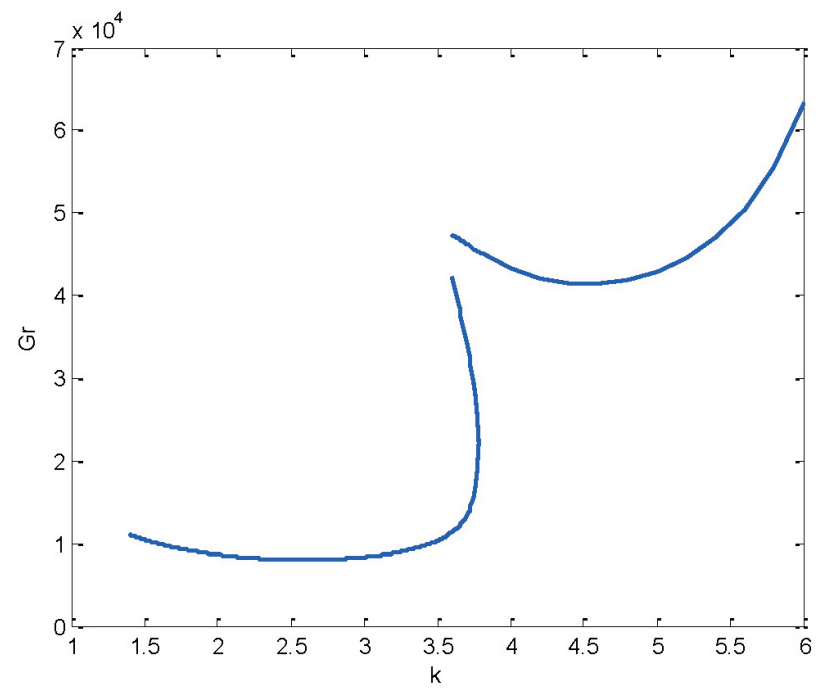

Fig. 7. Marginal stability curve for the case $\operatorname{Pr}=4, \alpha=1$.

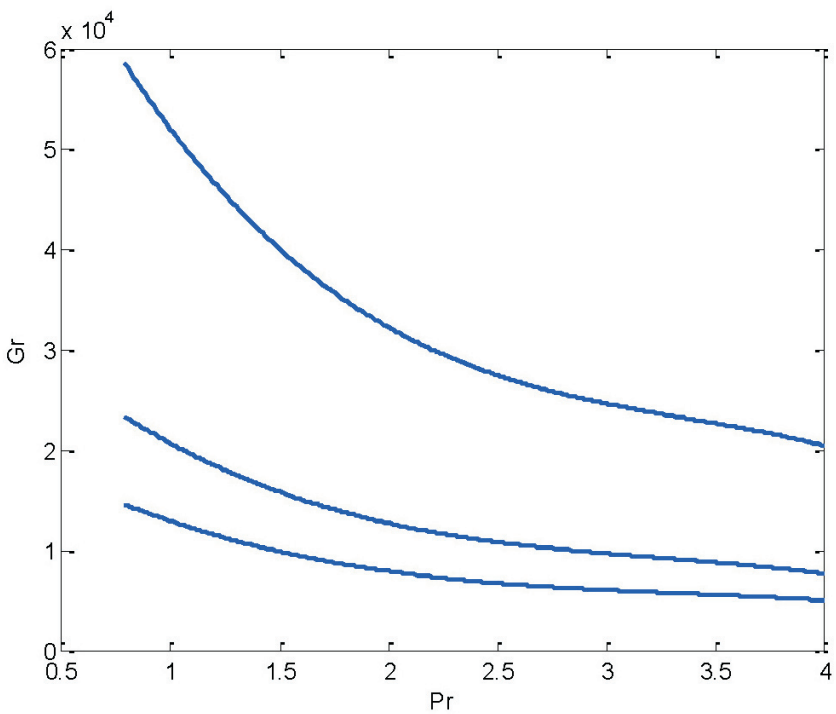

Fig. 8. Critical values of the Grashof number versus $\mathrm{Pr}$ for asymmetric perturbations with $n=1$ and $R=2$.

\section{CONCLUSIONS}

Linear stability of a steady convective motion of a viscous incompressible fluid in a tall vertical annulus with respect to axisymmetric and asymmetric perturbations was investigated. The flow was caused by non-uniform heat sources distributed within the fluid. Three destabilising factors were identified: (a) the increase of the gap between cylinders destabilised the flow, (b) higher concentration of the heat sources close to the outer boundary destabilised the flow, and (c) the increase of the Prandtl number also destabilised the flow.

Experimental studies of biomass thermal conversion ( $\mathrm{Ab}$ ricka et al., 2016; Barmina et al., 2016) showed that other factors such as applied magnetic field or swirling flow of supply air could substantially modify the flow structure and result in more efficient energy conversion. The authors are currently working on the problem of stability of a convective flow in a magnetic field. Rotation of the cylinders in opposite directions may lead to instability, which, in turn, can enhance mixing. Investigation of the effects of rotation on the stability of a convective flow caused by non-uniform heat sources will be analysed in future work.

\section{REFERENCES}

Abricka, M., Barmina, I., Purmalis, M., Valdmains, R., Zake, M., Kalis, H. (2016). Experimental and numerical studies on integrated gasification and combustion of biomass. Chem. Eng. Trans., 50, 127-132.

Barmina, I., Purmalis, M., Valdmains, R., Zake, M. (2016). Electrodynamic control of the combustion characteristics and heat energy production. Combustion Sci. Tech., 188, 190-206.

Gershuni, G. Z., Zhukhovitskii, E. M., Iakimov, A. A. (1970). On the stability of steady convective motion generated by internal heat sources. J. Appl. Math. Mech., 34, 700-705

Gershuni, G. Z., Zhukhovitskii, E. M., Iakimov, A. A. (1973). Two kinds of instability of stationary convective motion induced by internal heat sources. J. Appl. Math. Mech., 37, 564-568.

Iltina, M., Iltins, I., Kolyshkin, A. (2017). Convective stability of a chemically reacting fluid in annulus. In: Proceedings of the $7^{\text {th }}$ International Conference on Computational Methods for Coupled Problems in Science and Engineering, 12/14 June 2017, Rhodes Island, Greece, pp. 427-433.

Koliskina, V., Kolyshkin, A., Volodko, I., Kalis, H. (2016). On the stability of a convective motion generated by a chemically reacting fluid in a pipe. In: Amer. Inst. Phys. Conf. Proc., 1738 (1), 480028.

Kolyshkin, A., Koliskina, V. (2018a). Linear stability analysis of a convective flow in a pipe due to radially distributed heat sources. In: Proceedings of the 17th International Scientific Conference Engineering for Rural Development, 23-25 May, 2018, Jelgava, Latvia, pp. 1289-1294.

Kolyshkin, A., Koliskina, V. (2018b). Stability of a convective flow in a pipe caused by internal heat generation. JP J. Heat Mass Transfer, 15, 515-530.

Kolyshkin, A. A., Vaillancourt, R. (1991). Stability of internally generated thermal convection in a tall vertical annulus. Can J. Phys., 69, 743-748.

Su, Y. C., Chung, J. N. (2000). Linear stability analysis of mixed-convection flow in a vertical pipe. J. Fluid Mech., 422, 141-166.

Yao, L. S. (1987). Is a fully developed and non-isothermal flow possible in a vertical pipe? Int. J. Heat Mass Transfer., 30, 707-716.

Received 12 April 2019

Accepted in the final form 27 June 2020 

DIVIEM KONCENTRISKIEM CILINDRIEM

Rakstā izpētīta konvektīvās kustības lineārā stabilitāte apgabalā starp diviem koncentriskiem cilindriem. Bāzes plūsmu izraisa siltuma avoti, kas ir nevienmērīgi sadalīti radiālā virzienā. Bāzes plūsmas ātrumu un temperatūru iegūst analītiski, risinot Navjē-Stoksa vienādojumu sistēmu Busineska tuvinājumā. Lineārās stabilitātes problēma ir atrisināta simetriskām un nesimetriskām perturbācijām ar kolokācijas metodi, kuras pamatā ir Čebiševa polinomi. Skaitliskie rezultāti rāda, ka pastāv trīs destabilizējošie faktori: (1) attāluma starp cilindriem palielināšanās, (2) iekšējo siltuma avotu palielināšanās virzienā uz apgabala ārējo robežu un (3) Prandța skaitḷa palielināšanās. 